\title{
Оценка ставки восстановления по российским корпоративным облигациям
}

\begin{abstract}
Антонова E.H. ${ }^{30}$
Ставка восстановления является одним из ключевых параметров оченки возможных потерь при наступлении дефолта по корпоративной облигации наряду с вероятностью дефолта и подверженностью риску при наступлении дефолта. Она показывает, какую долю привлеченных средств эмитент возвращяат владельиу облигачии в случае ее дефолта. Однако оценке ставки восстановления, в отличие от оценки вероятности дефолта, долгое время не уделялось достаточного внимания в научных работах. Цель настоящего исследования - создать модель для оценки ставки восстановления по корпоративным облигаџиям российских эмитентов.
\end{abstract}

\section{$J E L: G 32$}

Ключевые слова на русском: ставка восстановления, дефолт, уровень потерь при наступлении дефолта, корпоративные облигации

\section{Введение}

Ставка восстановления является одним из ключевых параметров оценки возможных потерь при наступлении дефолта по корпоративной облигации наряду с вероятностью дефолта и подверженностью риску при наступлении дефолта. Она показывает, какую долю привлеченных средств эмитент возвращает владельцу облигации в случае ее дефолта. Однако оценке ставки восстановления, в отличие от оценки вероятности дефолта, долгое время не уделялось достаточного внимания в научных исследованиях.

Интерес к оценке ставки восстановления возник в последнее десятилетие, а проведенные исследования главным образом ограничиваются западными финансовыми рынками. Изворски (Izvorski,1997) одним из первых определил совокупность факторов, объясняющих ставку восстановления, и установил значимость зависимости от старшинства обязательства в структуре долга заемщика, темпа роста в отрасли и типа реструктуризации. Существенный вклад в определение совокупности объясняющих факторов, влияющих на ставку восстановления по долговым обязательствам на международных рынках, внесли работы Альтмана (Altman, Brady, Resti, Sironi, 2001), Ачарии (Acharya, Bharath, Srinivasan, 2003), Гуптона и Стейна (Gupton, Stein, 2002), Варма (Varma, Cantor, 2004), Эберхарта и Вейса (Eberhart, Weiss, 1992), Шлейфера и Вишни (Shleifer, Vishny, 1992), Джейкобса (Jacobs, Karagozoglu, 2010), Ковица и Хана (Covitz, Han,2004), Фрай (Frye, 2000), Франка (Franks, Torous, 2000) и Шурмана (Schuermann, 2004). Обзор научных исследований по данной теме проводится в работе Е. Антоновой »Обзор моделей оценки ставки восстановления по корпоративным облигациям».

Российский рынок корпоративных облигаций продолжает расти высокими темпами и обладает повышенным потенциалом развития в сравнении с западными рынками. В зависимости от темпа экономического роста и степени финансово-хозяйственной активности в стране активный рост совокупного номинала и количества эмиссий сменяется периодами спада, в которых возрастает количество дефолтов. Поэтому проблема оценки ставки восстановления особенно остро стоит перед отечественной финансовой наукой и определяет цель настоящего исследования - создать модель для оценки ставки восстановления по

\footnotetext{
30 Аспирантка, Национальный исследовательский университет «Высшая школа экономики», специальность «Финансы и кредит».
} 
корпоративным облигациям российских эмитентов.

\section{Факторы, объясняющие ставку восстановления по корпоративным обязательствам российских эмитентов \\ Статистическая выборка исследования}

По данным информационно-аналитического агентства Cbonds, за период наблюдения с 31 декабря 2002 года по 31 декабря 2011 года 124 российских корпоративных эмитента допустили реальный дефолт по рублевым корпоративным облигациям, которые обращались на ММВБ. Под реальным дефолтом понимается неисполнение обязательства эмитента по облигации до истечения льготного периода.

В качестве метода расчета ставки восстановления в настоящем исследовании был выбран метод расчета «восстановление по отношению к номинальной стоимости облигации» (Антонова, 2012)), согласно которому ставка восстановления рассчитывается как отношение рыночной стоимости облигации после дефолта к ее номинальной стоимости. Алгоритм расчета ставки восстановления представлен на рисунке 1.

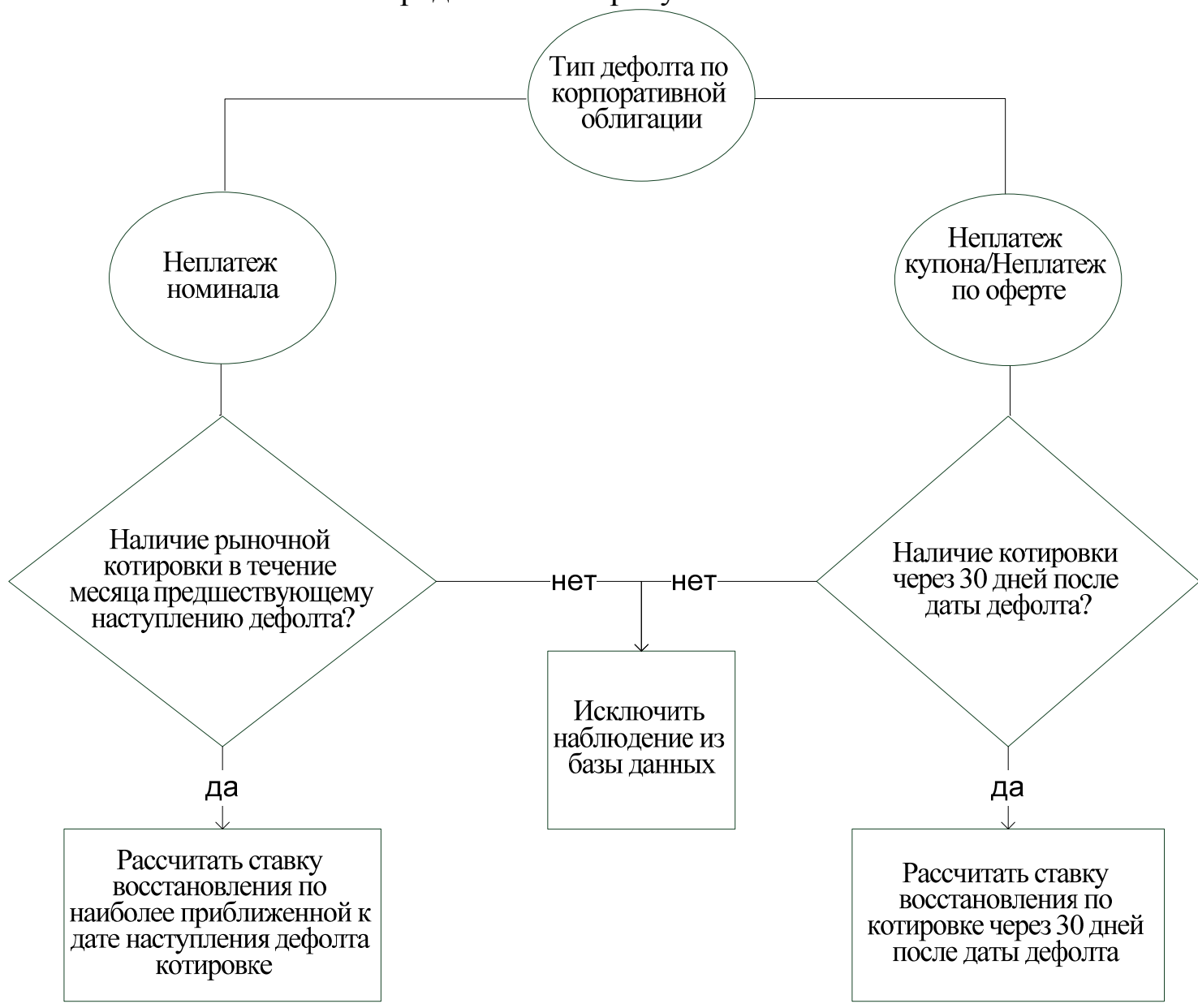

Рисунок 1. Алгоритм расчета ставки восстановления по корпоративным облигациям

На основании выбранного метода расчета ставки восстановления были рассчитаны по 59 дефолтам корпоративных облигаций, выпущенных 58 российскими эмитентами, которые сформировали статистическую выборку настоящего исследования. Статистическая выборка включает два случая дефолта по облигациям одного эмитента (ОАО «ИНПРОМ»), которые произошли с интервалом в два с лишним года.

Опираясь на полученные результаты систематизации факторов (Антонова, 2011), объясняющих ставку восстановления на международных рынках, в данном разделе автор описывает зависимость ставки восстановления по корпоративным облигациям российских эмитентов от 17 факторов. Указанные факторы разделены на четыре группы:

1. Специфические факторы на уровне облигации. 
2. Специфические факторы на уровне компании.

3. Отраслевая принадлежность.

4. Макроэкономическая ситуация.

\section{Специфические факторы на уровне облигации Тип дефолта}

В настоящем исследовании под дефолтом понимается невыплата платежа по купону или номиналу облигации или неисполнение оферты эмитентом корпоративной облигации с учетом льготного периода. Зависимость ставки восстановления от типа дефолта представлена в таблице 1 .

Таблица 1

Ставка восстановления в зависимости от типа дефолта

\begin{tabular}{|l|c|c|c|c|}
\hline \multicolumn{1}{|c|}{ Тип дефолта } & $\begin{array}{c}\text { Среднее } \\
\text { значение ставки } \\
\text { восстановления, } \\
\text { \% }\end{array}$ & $\begin{array}{c}\text { Стандартное } \\
\text { отклонение, } \\
\text { \% }\end{array}$ & $\begin{array}{c}\text { Количество } \\
\text { наблюде- } \\
\text { ний }\end{array}$ & $\begin{array}{c}\text { Отношение } \\
\text { неисполненног } \\
\text { о обязательства } \\
\text { к номиналу } \\
\text { облигации, \% }\end{array}$ \\
\hline Невыплата купона & 35,4 & 28,2 & 21 & 4,2 \\
\hline $\begin{array}{l}\text { Неисполнение } \\
\text { оферты }\end{array}$ & 47,0 & 21,2 & 22 & 64,3 \\
\hline $\begin{array}{l}\text { Невыплата } \\
\text { номинала }\end{array}$ & 68,7 & 30,3 & 16 & 87,0 \\
\hline Общий итог & 48,8 & 29,1 & 59 & 49,1 \\
\hline
\end{tabular}

Наименьшее значение средняя ставка восстановления принимает в случае невыплаты купона. Неспособность эмитента изыскать относительно невысокий объем средств, необходимый для выплаты купона по облигации, свидетельствует о существенном ухудшении его кредитного качества и серьезных затруднениях с ликвидностью, которые эмитенту не удается преодолеть.

Наибольшее восстановление наблюдается в случае невыплаты номинала облигации, в среднем составляя $68,7 \%$. Наивысший уровень средней ставки восстановления в разрезе типа дефолта объясняется тем, что, несмотря на ухудшившееся кредитное качество, эмитент был способен рефинансировать часть своей задолженности и изыскать средства на выплату купонов по облигации. Это является положительным сигналом, свидетельствующим о меньших затруднениях с ликвидностью эмитента в сравнении с дефолтом вследствие невыплаты купона.

Сумма обязательства, которую эмитент способен рефинансировать, находится в обратной зависимости от его финансового положения и, соответственно, от ставки восстановления. В таблице 1 просматривается положительная зависимость в разрезе типа дефолта между средней ставкой восстановления и отношением суммы неоплаченного обязательства к основной сумме облигации, по которой произошел дефолт. Относительная сумма просрочки платежа может рассматриваться как количественный показатель типа дефолта, принимающий минимальное значение в случае невыплаты купона, промежуточное в случае неисполнения оферты и максимальное в случае невыплаты номинала облигации.

\section{Реструктуризация}

В случае невыполнения заемщиком своих обязательств по обслуживанию долга кредитор вправе требовать возмещения понесенных потерь посредством судебного разбирательства или попытаться реструктурировать долг в ходе внесудебных переговоров с заемщиком. В данной работе под реструктуризацией понимается соглашение между должником и кредиторами относительно изменения условий существующих обязательств должника перед кредиторами с целью повышения вероятности их исполнения. 
Проведение реструктуризации оказывает разнонаправленное воздействие на ставку восстановления. С одной стороны, проведение реструктуризации при наступлении дефолта потенциально способствует увеличению ставки восстановления по корпоративной облигации, так как нацелено на сотрудничество между эмитентом и кредиторами с целью избежать затратной и продолжительной процедуры банкротства эмитента. С другой стороны, факт проведения реструктуризации свидетельствует о существенных финансовых трудностях заемщика, которые не всегда могут быть успешно преодолены. Как правило, проведение реструктуризации свидетельствует о том, что возможности рефинансирования исчерпаны и не привели к успеху. Зависимость ставки восстановления от факта проведения реструктуризации представлена в таблице 2 .

Таблица 2

Ставка восстановления в случае реструктуризации

\begin{tabular}{|l|c|c|c|}
\hline & $\begin{array}{c}\text { Среднее } \\
\text { значение, \% }\end{array}$ & $\begin{array}{c}\text { Стандартное } \\
\text { отклонение, \% }\end{array}$ & $\begin{array}{c}\text { Количество } \\
\text { наблюдений }\end{array}$ \\
\hline Проведение реструктуризации & 47,8 & 26,2 & 31 \\
\hline Отсутствие реструктуризации & 49,8 & 32,6 & 28 \\
\hline Общий итог & 48,8 & 29,1 & 59 \\
\hline
\end{tabular}

Средняя ставка восстановления в случае проведения реструктуризации незначительно отличается от средней доли восстановления, достигнутой без изменения изначальных условий обязательств эмитента. Реструктуризация приводит к снижению неопределенности стандартное отклонение ставки восстановления составляет $26,2 \%$ в случае реструктуризации в сравнении с $32,6 \%$ в ее отсутствие.

Сила зависимости ставки восстановления от реструктуризации возрастает в случае включения в анализ фактора банкротства. В настоящем исследовании под банкротством понимается признанная арбитражным судом неспособность должника в полном объеме удовлетворить требования кредиторов по денежным обязательствам и (или) исполнить обязанность по уплате обязательных платежей (Федеральный закон «О несостоятельности (банкротстве)» от 26.10.2002 № 127-Ф3). В целях настоящего исследования в качестве признака банкротства принимается факт регистрации в Арбитражном суде РФ заявления эмитента о банкротстве. Зависимость ставки восстановления от факта реструктуризации, принимая во внимание банкротство, описана в таблице 3.

Таблица 3

Влияние реструктуризации и банкротства на ставку восстановления

\begin{tabular}{|l|c|c|c|c|}
\hline \multirow{2}{*}{ Реструктуризация } & $\begin{array}{c}\text { Банкрот- } \\
\text { ство }\end{array}$ & $\begin{array}{c}\text { Среднее } \\
\text { значение, \% }\end{array}$ & $\begin{array}{c}\text { Стандартное } \\
\text { отклонение, \% }\end{array}$ & $\begin{array}{c}\text { Количество } \\
\text { наблюдений }\end{array}$ \\
\hline \multirow{2}{*}{$\begin{array}{l}\text { Проведение } \\
\text { реструктуризации }\end{array}$} & да & 33,1 & 24,0 & 12 \\
\cline { 2 - 5 } $\begin{array}{l}\text { Отсутствие } \\
\text { реструктуризации }\end{array}$ & нет & 57,1 & 23,6 & 19 \\
\cline { 2 - 5 } Общий итог & нет & 40,8 & 34,4 & 18 \\
\hline
\end{tabular}

Ставка восстановления принимает наименьшее значение $(33,1 \%)$ в случае неуспешной реструктуризация, которая приводит к банкротству эмитента. Если реструктуризация успешна и позволяет избежать банкротства, средняя ставка восстановления возрастает до $57,1 \%$. В обоих случаях проведение реструктуризации снижает неопределенность относительно восстановления.

Если кредиторы отказываются от предлагаемых эмитентом условий реструктуризации и в одностороннем порядке принимают меры по взысканию задолженности в ходе 
процедуры банкротства эмитента, ставка восстановления составляет в среднем 40,8\%, что выше минимальной средней ставки восстановления $(33,1 \%)$, которая наблюдается в случае безуспешной реструктуризации и последующего банкротства эмитента. В то же время такая стратегия поведения кредиторов несет повышенные риски, о чем свидетельствует максимальное в рассматриваемом разрезе наблюдений значение стандартного отклонения $34,4 \%$ при среднем стандартном отклонении по выборке 29,1\%.

\section{Специфические факторы на уровне компании}

\section{Участие государства в финансово-хозяйственной деятельности эмитента}

Данный раздел посвящен описанию зависимости ставки восстановления от участия федеральных или региональных органов власти в производственно-хозяйственной деятельности эмитента в случае возникновения финансовых затруднений. В настоящем исследовании роль государства описывается тремя бинарными факторами: участие органов власти в собственном капитале эмитента, получение эмитентом адресных мер государственной поддержки и получение эмитентом общих мер государственной поддержки.

\section{Участие органов власти в собственном капитале эмитента}

Государство участвует в управлении эмитентом посредством назначения своих представителей в органы корпоративного управления, которое возможно в случае прямого или косвенного участия федеральных или региональных органов власти в собственном капитале эмитента. Статистическая выборка настоящего исследования содержит четыре случая дефолта по облигациям эмитентов с участием органов власти в собственном капитале.

Средняя ставка восстановления, рассчитанная по облигациям эмитентов с участием органов власти в собственном капитале, составляет 66,7\% и на 17,9 процентных пунктов превышает среднее значение по выборке, что объясняется более высокой вероятностью применения адресных мер государственной поддержки в отношении таких эмитентов. Трем из четырех эмитентов с участием органов власти в собственном капитале была оказана адресная государственная поддержка. Ставка восстановления по облигациям единственного в статистической выборке эмитента с участием органов власти в капитале, которому не была оказана государственная поддержка, составила минимальное значение в разрезе рассматриваемой группы эмитентов, а именно 29,9\%. Стандартное отклонение по группе составляет 36,3\%, что на 7,2 процентных пункта превышает стандартное отклонение, рассчитанное в целом по выборке. Более высокий разброс ставки восстановления может объясняться тем, что участие органов власти в капитале не всегда приводит к применению адресных мер государственной поддержки, способствующих более успешному восстановлению.

\section{Применение к эмитенту адресных мер государственной поддержки}

В настоящем исследовании под мерами адресной государственной поддержки понимаются конкретные действия федеральных или региональных органов государственной власти, направленные на восстановление финансовой устойчивости определенного эмитента. Данные меры включают размещение государственного заказа на продукцию эмитента, предоставление прямой государственной субсидии, предоставление государственной гарантии по банковским кредитам и выкуп облигаций эмитента на вторичном рынке. Круг получателей адресной государственной поддержки не ограничивается организациями с государственным участием в собственном капитале, а также включает корпоративных эмитентов, находящихся в полной частной собственности. Основным критерием применения адресных мер государственной поддержки является не столько структура собственности, сколько системная значимость организации в экономике и ее социальная роль в регионе. Статистическая выборка настоящего исследования содержит 12 наблюдений по дефолтам частных корпоративных эмитентов, по отношению к которым органы государственной 
власти приняли адресные меры государственной поддержки. Зависимость ставки восстановления от применения адресных мер государственной поддержки в разрезе типа структуры собственности представлена в таблице 4.

Таблица 4

Ставка восстановления в зависимости от применения адресных мер государственной поддержки и участия органов власти в капитале эмитента

\begin{tabular}{|l|c|c|c|c|}
\hline $\begin{array}{c}\text { Адресные меры } \\
\text { господдержки }\end{array}$ & $\begin{array}{c}\text { Участие органов } \\
\text { власти в капитале }\end{array}$ & $\begin{array}{c}\text { Среднее } \\
\text { значение, \% }\end{array}$ & $\begin{array}{c}\text { Стандартное } \\
\text { отклонение, } \\
\text { \% }\end{array}$ & $\begin{array}{c}\text { Количество } \\
\text { наблюдений }\end{array}$ \\
\hline \multirow{2}{*}{ Применены } & да & 78,9 & 32,9 & 3 \\
\cline { 2 - 5 } & нет & 56,8 & 29,1 & 12 \\
\hline Промежуточный итог & & 61,2 & 30,0 & 15 \\
\hline \multirow{2}{*}{ Не применены } & да & 30,0 & неприменимо & 1 \\
\hline Промежуточный итог & нет & 44,9 & 28,2 & 43 \\
\hline Общий итог & & 44,5 & 27,9 & 44 \\
\hline
\end{tabular}

Ставка восстановления составляет $61,2 \%$ в случае получения адресной государственной поддержки и существенно превышает среднее восстановление в размере 44,5\%, если адресная государственная поддержка отсутствует. Максимально эффективна адресная поддержка в случае участия органов власти в капитале: средняя ставка восстановления в этом случае на 30,1 процентных пункта выше среднего значения по статистической выборке. Стандартное отклонение ставки восстановления в случае получения адресной поддержки государства близко к среднему по выборке и составляет $30,0 \%$.

\section{Применение к эмитенту общих мер государственной поддержки}

Под общими мерами государственной поддержки в настоящем исследовании понимаются действия федеральных органов государственной власти, направленные на изменение условий финансово-хозяйственной деятельности определенной целевой группы организаций с целью поддержки их финансовой устойчивости. Общие меры государственной поддержки включают как принятые нормативные акты, так и действия по формированию и поддержанию в профессиональной среде участников финансового рынка мнения о готовности и способности органов федеральной власти оказывать поддержку целевой группе хозяйствующих субъектов.

В настоящей работе признаком получения общей государственной поддержки является включение эмитента в «Перечень системообразующих организаций» пресс-службы Министерства экономического развития РФ.

Статистическая выборка настоящего исследования содержит 10 эмитентов, которые были включены в «перечень системообразующих организаций», причем только шесть из них получили адресную государственную поддержку. В таблице 5 представлена зависимость ставки восстановления от применения общих мер государственной поддержки в разрезе применения адресных мер государственной поддержки. 
Ставка восстановления в зависимости от применения общих и адресных мер государственной поддержки

\begin{tabular}{|l|c|c|c|c|}
\hline \multicolumn{1}{|c|}{ Общие меры } & $\begin{array}{c}\text { Адресные } \\
\text { меры }\end{array}$ & $\begin{array}{c}\text { Среднее } \\
\text { значение, \% }\end{array}$ & $\begin{array}{c}\text { Стандартное } \\
\text { отклонение, \% }\end{array}$ & $\begin{array}{c}\text { Количество } \\
\text { наблюдений }\end{array}$ \\
\hline \multirow{2}{*}{ Применены } & да & 53,9 & 26,2 & 6 \\
\cline { 2 - 5 } & нет & 46,3 & 3,1 & 3 \\
\hline \multirow{2}{*}{ Промежуточный итог } & & 51,4 & 21,1 & 9 \\
\hline Пр применены & да & 66,0 & 33,0 & 41 \\
\cline { 2 - 5 } & нет & 44,4 & 28,9 & 50 \\
\hline Общий итог & & 48,3 & 30,5 & 59 \\
\hline
\end{tabular}

Средняя ставка восстановления, рассчитанная по 9 эмитентам, состоящим в «Перечне системообразующих организаций», составляет 51,4\%, что на 2,6 процентных пункта выше, чем средняя ставка восстановления в целом по выборке. Незначительное отличие от среднего значения по выборке свидетельствует о низком влиянии общих мер государственной поддержки на ставку восстановления по сравнению с применением адресных мер, где разница со средним по выборке составляет 12,4 процентных пункта. Разброс значений ставки восстановления по эмитентам, входящим в перечень, составляет $21,1 \%$, что на 8 процентных пунктов ниже среднего по выборке, что свидетельствует о большей определенности относительно восстановления по неисполненным корпоративным облигациям этих эмитентов.

Более успешному восстановлению по эмитентам, включенным в «Перечень системообразующих организаций», способствовало применение адресных мер государственной поддержки (см. табл. 5). Средняя ставка восстановления в этом случае составляет 53,9\%, что на 7,6 процентных пункта выше средней ставки восстановления в случае отсутствия адресных мер государственной поддержки.

Подводя итог, можно сказать, что средняя ставка восстановления достигает максимального значения $78,9 \%$ в случае применения адресных мер при участии государственных органов власти в собственном капитале эмитента. Следующее наиболее высокое значение средней ставки восстановления наблюдается при применении только адресных мер - 59,6\%. Самое низкое значение средняя ставка восстановления принимает в случае отсутствия адресных и общих мер государственной поддержки, причем как в случае полной частной собственности $(44,4 \%)$, так и при участии органов власти в собственном капитале эмитента $(30,0 \%)$.

\section{Кредитование государственными банками}

Настоящий раздел посвящен анализу зависимости ставки восстановления от участия государственных банков в рефинансировании обязательств эмитента.

Доминирующее положение в российской банковской системе занимают банки, контролируемые государством, которые имеют долю рынка свыше 50\% по активам по данным Банка России. В статистической выборке настоящего исследования 42 из 59 эмитентов привлекали кредиты от банков, находящиеся под прямым или косвенным контролем федерального правительства. Основными кредиторами выступали ОАО «Сбербанк», ОАО «Банк ВТБ», Внешэкономбанк и ОАО «Россельхозбанк». Средняя ставка восстановления в случае привлечения эмитентом кредитов от государственных банков составляет 48,2\% и незначительно отличается от средней ставки восстановления 50,2\%, рассчитанной по облигациям эмитентов, которые в основном заимствовали у частных банков (см. табл. 6). В обоих случаях ставка восстановления близка к среднему значению по выборке $-48,8 \%$. 
Кредитование государственными банками оказывает более заметное влияние на ставку восстановления в случае получения эмитентом адресной государственной поддержки. Государственные банки принимали участие в рефинансировании обязательств каждого из 15 эмитентов статистической выборки настоящего исследования, по отношению к которым применялись адресные меры государственной поддержки. В этом случае средняя ставка восстановления достигает максимального значения $(61,2 \%)$ в рассматриваемом разрезе данных при среднем восстановлении по статистической выборке 48,8\%. Тем не менее участие государственных банков в рефинансировании обязательств эмитента, которому государство оказывает адресную поддержку, не приводит к повышению определенности относительно результата восстановления по его облигациям. Разброс ставки восстановления в случае привлечения эмитентом кредитов государственных банков и при получении адресной государственной поддержки близок к среднему значению стандартного отклонения по выборке.

Таблица 6

Зависимость ставки восстановления от кредитования государственными банками и получения адресной государственной поддержки

\begin{tabular}{|c|c|c|c|c|}
\hline $\begin{array}{c}\text { Кредиторы- } \\
\text { госбанки }\end{array}$ & $\begin{array}{c}\text { Адресные } \\
\text { меры }\end{array}$ & $\begin{array}{c}\text { Среднее } \\
\text { значение, } \\
\text { \% }\end{array}$ & $\begin{array}{c}\text { Стандартное } \\
\text { отклонение, \% }\end{array}$ & $\begin{array}{l}\text { Количество } \\
\text { наблюдений }\end{array}$ \\
\hline \multirow{2}{*}{ Да } & да & 61,2 & 30,0 & 15 \\
\hline & нет & 41,0 & 26,0 & 27 \\
\hline $\begin{array}{l}\text { Промежуточный } \\
\text { итог }\end{array}$ & & 48,2 & 28,9 & 42 \\
\hline Нет & нет & 50,2 & 30,7 & 17 \\
\hline $\begin{array}{l}\text { Промежуточный } \\
\text { итог }\end{array}$ & & 50,2 & 30,7 & 17 \\
\hline Общий итог & & 48,8 & 29,1 & 59 \\
\hline
\end{tabular}

В отсутствие адресной государственной поддержки кредитование государственных банков оказывает негативное влияние на результат восстановления. Благодаря сильной переговорной позиции, государственные банки могут договариваться с заемщиком о предпочтительных условиях возврата банковского кредита, в некоторых случаях - в ущерб интересам необеспеченных кредиторов, включая владельцев корпоративных облигаций. Без адресной поддержки государства средняя ставка восстановления заемщиков государственных банков составляет $41,0 \%$ по сравнению со средней ставкой восстановления $50,2 \%$, рассчитанной по эмитентам, не имеющим кредитов государственных банков.

Кредитование у государственных банков также оказывает отрицательное влияние на ставку восстановления по корпоративным облигациям в случае банкротства эмитента. Статистическая база настоящего исследования содержит 30 случаев банкротства эмитентов, 18 из которых были заемщиками государственных банков. Средняя ставка восстановления при участии государственных банков в кредитовании составляет в случае банкротства $33,1 \%$, что на 11,5 процентных пункта ниже средней ставки восстановления $44,6 \%$ в случае рефинансирования обязательств эмитента преимущественно у частных банков. Восстановление в случае участия государственных банков в кредитовании эмитента более плотно сосредоточено относительно среднего, о чем свидетельствует стандартное отклонение $28,4 \%$, на 4,8 процентных пункта ниже стандартного отклонения при кредитовании у частных банков. Зависимость ставки восстановления от кредитования государственными банками в случае банкротства эмитента показана в таблице 7. 
Таблица 7

Зависимость ставки восстановления от кредитования государственными банками в случае банкротства эмитента

\begin{tabular}{|l|c|c|c|c|}
\hline $\begin{array}{c}\text { Кредиторы - } \\
\text { государственные банки }\end{array}$ & Банкротство & $\begin{array}{c}\text { Среднее } \\
\text { значение, \% }\end{array}$ & $\begin{array}{c}\text { Стандартное } \\
\text { отклонение, } \\
\text { \% }\end{array}$ & $\begin{array}{c}\text { Количество } \\
\text { наблюдений }\end{array}$ \\
\hline \multirow{2}{*}{ Да } & да & 33,1 & 28,4 & 18 \\
\cline { 2 - 5 } & нет & 59,5 & 24,0 & 24 \\
\hline Промежуточный итог & & 48,2 & 28,9 & 42 \\
\hline \multirow{2}{*}{ Нет } & да & 44,6 & 33,2 & 12 \\
\hline Промежуточный итог & нет & 63,7 & 20,4 & 5 \\
\hline Общий итог & & 50,2 & 30,7 & 17 \\
\hline
\end{tabular}

\section{Признаки противоправных действий органов корпоративного управления эмитента}

В настоящем исследовании под противоправными действиями органов корпоративного управления эмитента понимается их виновное действие или бездействие, противоречащее требованиям законодательства Российской Федерации (Уголовный кодекс РФ, ста. 159 «Мошенничество» и ст. 196 «Преднамеренное банкротство»).

Статистическая база настоящего исследования содержит 10 случаев, в которых присутствовали признаки мошенничества или действий, совершенных с целью преднамеренного банкротства эмитента. Как правило, информация о признаках противоправных действий органов корпоративного управления эмитента становится публичной, если инициируется процедура банкротства. Во всех 10 наблюдениях статистической базы настоящего исследования, в которых присутствовали признаки противоправных действий органов корпоративного управления, эмитенты признавались банкротами. Зависимость ставки восстановления от признаков противоправных действия органов корпоративного управления эмитента и банкротства представлена в таблице 8.

Таблица 8

Зависимость ставки восстановления от признаков противоправных действия органов корпоративного управления эмитента и банкротства

\begin{tabular}{|l|c|c|c|c|}
\hline $\begin{array}{c}\text { Признаки } \\
\text { противоправных } \\
\begin{array}{c}\text { действий органов } \\
\text { управления }\end{array}\end{array}$ & Банкротство & $\begin{array}{c}\text { Среднее } \\
\text { значение, \% }\end{array}$ & $\begin{array}{c}\text { Стандартное } \\
\text { отклонение, \% }\end{array}$ & $\begin{array}{c}\text { Количество } \\
\text { наблюдений }\end{array}$ \\
\hline Да & да & 24,8 & 19,5 & 10 \\
\hline Промежуточный итог & & 24,8 & 19,5 & 10 \\
\hline \multirow{2}{*}{ Нет } & да & 44,2 & 33,5 & 20 \\
\cline { 2 - 5 } & нет & 60,2 & 23,1 & 29 \\
\hline Промежуточный итог & & 53,7 & 28,5 & 49 \\
\hline Общий итог & & 48,8 & 29,2 & 59 \\
\hline
\end{tabular}

Обнаружение признаков противоправных действий органов корпоративного управления с высокой степенью определенности свидетельствует о существенно более низком восстановлении. В этом случае средняя ставка восстановления составляет $24,8 \%$, что на 24 процентных пункта ниже среднего значения по выборке. Ставка восстановления при наличии признаков противоправных действий органов корпоративного управления эмитента плотно сосредоточена около среднего, при стандартном отклонении 19,5\%, что на 9,7 процентных пунктов ниже среднего стандартного отклонения по выборке. 


\section{Финансовое положение эмитента}

В настоящей работе зависимость ставки восстановления от финансового положения эмитента исследуется в разрезе долговой нагрузки, доли основных фондов в активах и рентабельности финансово-хозяйственной деятельности. В то время как все эмиссии статистической базы настоящего исследования обеспечены поручительством других компаний, но консолидированная финансовая отчетность групп отсутствует, финансовые коэффициенты на уровне эмитента рассчитывались на основе суммированных показателей бухгалтерской отчетности эмитента и его поручителей. Расчет финансовых показателей осуществлялся на основании данных годовой финансовой отчетности, подготовленной по российским стандартам бухгалтерского учета за год, предшествующий дате дефолта эмитента.

\section{Долговая нагрузка эмитента}

В научных исследованиях ряда авторов (Acharya, Bharath, Srinivasan, 2003 \& Izvorski, 1997) было установлено, что зависимость ставки восстановления от долговой нагрузки эмитента неоднозначна. В настоящем исследовании зависимость ставки восстановления от долговой нагрузки эмитента оценивается на основании трех финансовых коэффициентов: отношение совокупных обязательств к собственному капиталу, отношение долгосрочных обязательств к собственному капиталу и доля собственного капитала в валюте баланса.

В статистической выборке настоящего исследования ставка восстановления имеет положительную корреляцию с отношением совокупных обязательств к собственному капиталу (коэффициент корреляции 0,03), но коэффициенты корреляции между ставкой восстановления и отношением долгосрочных обязательств к собственному капиталу и долей собственного капитала в валюте баланса отрицательны: -0,02 и -0,10 соответственно. Близкие к нулю значения коэффициентов детерминации R2 однофакторных регрессий ставки восстановления в зависимости от коэффициентов финансового рычага и доли собственного капитала в валюте баланса свидетельствуют о низкой статистической значимости этих взаимосвязей.

\section{Доля основных фондов в активах}

Под основными фондами понимаются активы компании, используемые в производственном процессе, со сроком службы, как правило, свыше года, которые не предназначены для продажи в рамках основной хозяйственной деятельности: например, земля, здания, оборудование и пр. Доля основных фондов в активах - показатель, позволяющий оценить ликвидационную стоимость организации в случае дефолта. В проведенных ранее эмпирических исследованиях Изворски (Izvorski, 1997), Ачария (Acharya, Bharath, Srinivasan, 2003) и Варма (Varma, Cantor, 2004) было установлено, что влияние данного показателя на значение ставки восстановления также неоднозначно. С одной стороны, высокая доля основных фондов в активах свидетельствует о материальной оснащенности компании, ведении реальной хозяйственной деятельности, а также о потенциально более высокой ликвидационной стоимости компании. С другой стороны, в сложных финансовых условиях балансовая стоимость основных фондов может превышать их ликвидационную стоимость, так как рыночный спрос на активы материальной базы снижается, а компании могут снижать капитальные инвестиции и замедлять замещение основных фондов, что приводит к их ускоренному устареванию и утрате ценности. В этом случае между ставкой восстановления и долей основных средств в общих активах компании может наблюдаться отрицательная зависимость.

В статистической выборке настоящего исследования зависимость ставки восстановления от доли основных фондов в активах эмитента положительная, с коэффициентом корреляции 0,08. Статистическая значимость однофакторной регрессии ставки восстановления от доли основных фондов в активах низкая, о чем свидетельствует 
низкое значение коэффициента детерминации R2.

\section{Рентабельность финансово-хозяйственной деятельности}

Проведенные эмпирические исследования обнаруживают положительную взаимосвязь между ставкой восстановления и рентабельностью финансово-хозяйственной деятельности на зарубежных рынках (Acharya, Bharath, Srinivasan, 2003). Высокая рентабельность свидетельствует об успешной финансово-хозяйственной деятельности компании и больших возможностях для исполнения долговых обязательств своевременно и в полном объеме. Экономическая взаимосвязь предполагает положительную корреляцию между ставкой восстановления и рентабельностью. В настоящем исследовании зависимость ставки восстановления от рентабельности финансово-хозяйственной деятельности эмитента оценивается на основании трех коэффициентов рентабельности: рентабельности продаж, рентабельности активов и рентабельности капитала.

Рентабельность продаж - финансовый показатель, равный отношению чистой прибыли к выручке. Рентабельность капитала - финансовый показатель, равный отношению чистой прибыли к величине собственного капитала. Рентабельность активов равна отношению чистой прибыли к величине активов.

В статистической выборке настоящего исследования зависимость ставки восстановления от коэффициентов рентабельности эмитента отрицательная. На статистической выборке настоящего исследования статистическая значимость однофакторных регрессий ставки восстановления от коэффициентов рентабельности низкая.

\section{Отраслевая принадлежность}

В ряде эмпирических исследований изучается зависимость между ставкой восстановления и отраслевой принадлежностью эмитента (Altman, Brady, Resti, Sironi, 2001). В настоящем исследовании эмитенты статистической выборки классифицированы в шесть отраслевых групп.

Как и на зарубежных рынках, средняя ставка восстановления по облигациям российских эмитентов существенно различается по отраслям. Среднеотраслевая ставка восстановления находится в интервале значений от 19,4\% в легкой промышленности до $64 \%$ в тяжелой промышленности. В таблице 9 представлены значения ставки восстановления по отраслям.

Таблица 9

Средняя ставка восстановления по отраслям

\begin{tabular}{|l|c|c|c|}
\hline \multicolumn{1}{|c|}{ Название отрасли } & $\begin{array}{c}\text { Среднее } \\
\text { значение, \% }\end{array}$ & $\begin{array}{c}\text { Стандартное } \\
\text { отклонение, \% }\end{array}$ & $\begin{array}{c}\text { Количество } \\
\text { наблюдений }\end{array}$ \\
\hline Тяжелая промышленность & 63,3 & 25,0 & 11 \\
\hline Строительство & 57,2 & 27,0 & 18 \\
\hline $\begin{array}{l}\text { Сельское хозяйство и } \\
\text { пищевая промышленность }\end{array}$ & 50,6 & 30,0 & 15 \\
\hline Торговля & 48,5 & 29,0 & 4 \\
\hline Легкая промышленность & 19,4 & 10,0 & 5 \\
\hline Прочие услуги & 24,4 & 28,2 & 59 \\
\hline Общий итог & 48,8 & 29,2 & \\
\hline
\end{tabular}

Повышенное восстановление в отраслях тяжелой промышленности, строительстве и сельском хозяйстве и пищевой промышленности объясняется присутствием в этих отраслях ключевых предприятий российской экономики. К этим отраслям относятся 12 из 13 эмитентов статистической выборки, которым была оказана адресная государственная поддержка, а также все 10 эмитентов, на которые распространялись меры общей 
государственной поддержки.

\section{Макроэкономические факторы}

2.

Распределение средней ставки восстановления по годам дефолта показано на рисунке

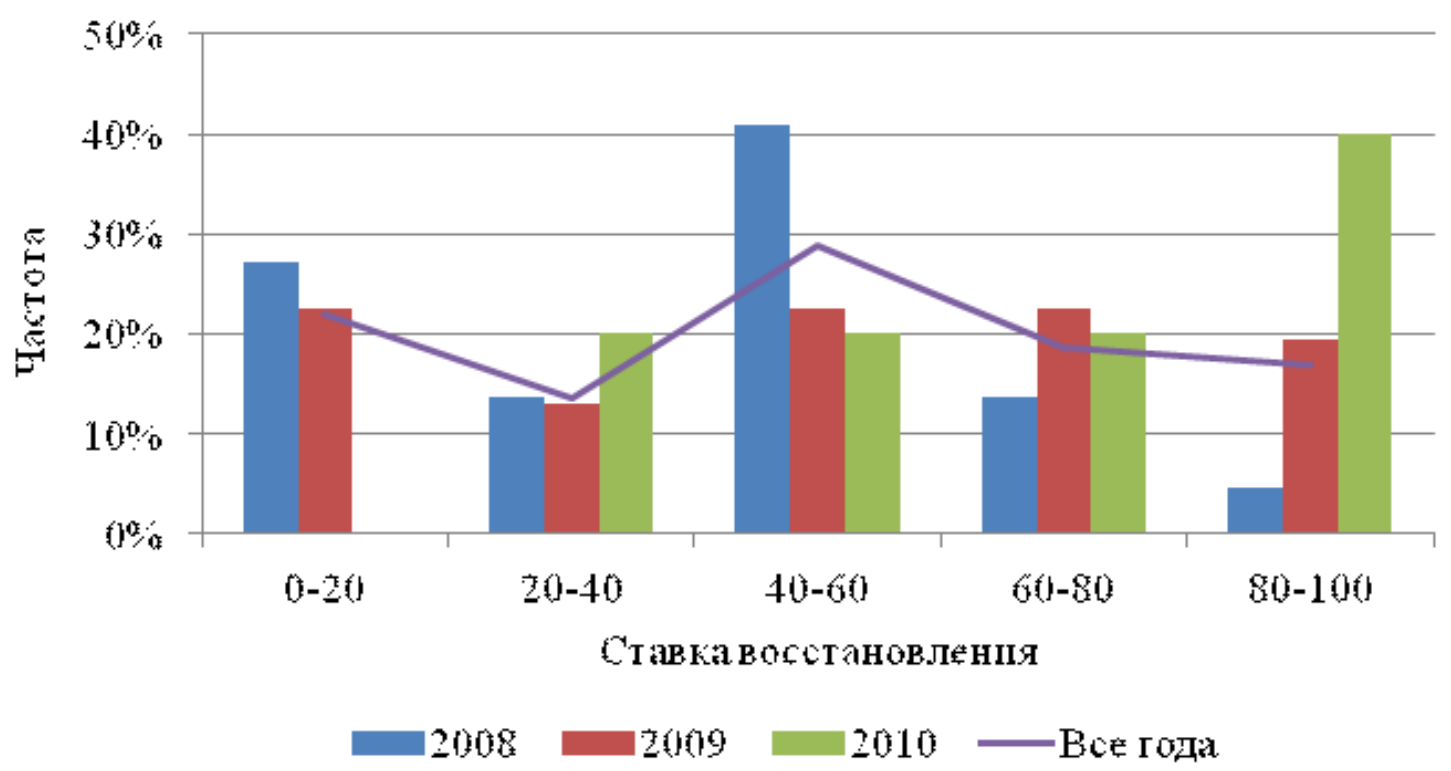

Рисунок 2. Распределение средней ставки восстановления по годам дефолта

В 2008 году наблюдалось большее количество дефолтов со ставкой восстановления 40$60 \%$, а также с низким восстановлением - 0-20\%, что объясняется началом финансового кризиса и высокой неопределенностью относительности эффективности мер государственной поддержки. В 2009 году началась стабилизация экономической ситуации, а также были применены общие и адресные меры государственной поддержки, что сместило плотность распределения ставки восстановления вправо: снизилось количество низких и средних ставок восстановления при одновременном увеличении количества высоких ставок восстановления. По мере дальнейшего восстановления экономики в 2010 году плотность распределения ставки восстановления еще сильнее сместилась в сторону более высоких значений, а средняя ставка восстановления увеличилась до 68,52\%.

\section{Оценка ставки восстановления}

В настоящем исследовании ставка восстановления оценивается методом регрессионного анализа. В качестве критериев эффективности регрессионного метода выбраны максимизация скорректированного коэффициента детерминации R2 при минимальной статистической значимости каждого коэффициента регрессии $10 \%$. Наиболее эффективная на полной статистической выборке модель представлена в таблице 10.

Таблица 10

Модель на полной статистической выборке

\section{Объясняющая переменная}

Константа

Бинарный индикатор участия государства в собственном
Коэффициент Уровень регрессии значимости

$\begin{array}{ll}76,33 & 0,0000 \\ 37,04 & 0,0041\end{array}$


капитале эмитента

Бинарный индикатор реструктуризации

Бинарный индикатор банкротства

$-19,97 \quad 0,0035$

$-15,41 \quad 0,0420$

Бинарный индикатор признаков противоправных действий

органов корпоративного управления эмитента

$-28,42 \quad 0,0027$

Бинарный индикатор кредитования эмитента

государственными банками

$-19,28 \quad 0,0087$

Бинарный индикатор отрасли «Тяжелая промышленность»

Бинарный индикатор отрасли «Прочие услуги»

$-28,90 \quad 0,0116$

Отношение суммы неисполненного обязательства к номиналу

$15,86 \quad 0,0544$

облигации

$12,85 \quad 0,0677$

$76,33 \quad 0,0000$

Регрессионная модель имеет высокую статистическую значимость, о чем свидетельствует скорректированный коэффициент детерминации R2 0,42. Bce коэффициенты регрессии значимы на уровне 5\%, за исключением бинарной переменной отрасли «Тяжелая промышленность» и отношения объема неисполненного обязательства к номиналу облигации, уровень значимости которых составляет 10\%. Полученные зависимости ставки восстановления от факторов соответствуют экономическому обоснованию, предложенному ранее.

Добавление в регрессионную модель финансовых показателей деятельности эмитента приводит к существенному снижению ее статистической значимости, а также сокращает значимость экономически обоснованных коэффициентов регрессии, в то время как статистическая значимость экономически противоречивых взаимосвязей возрастает.

Таким образом, наиболее эффективной моделью оценки ставки восстановления является уравнение регрессии, представленное в таблице 10, объясняющее ставку восстановления на основании набора качественных характеристик облигации и эмитента без отсылки к его финансовым показателям.

\section{Заключение}

Опираясь на полученные результаты систематизации факторов, объясняющих ставку восстановления на международных рынках, в данном исследовании предлагается экономическое обоснование зависимости ставки восстановления по корпоративным облигациям российских эмитентов от 17 факторов, включая факторы на уровне облигации, финансовые и нефинансовые факторы на уровне компании, отраслевые и макроэкономические факторы. Методом регрессионного анализа показано, что, во-первых, ставка восстановления по корпоративным облигациям российских эмитентов находится в статистически значимой зависимости от совокупности внешних и внутренних нефинансовых характеристик, в том числе макроэкономической ситуации и отраслевой принадлежности эмитента, в то время как включение финансовых показателей в набор объясняющих факторов приводит к снижению качества регрессионной модели. Во-вторых, на российском рынке корпоративных облигаций на ставку восстановления оказывают значимое влияние специфические факторы, в частности участие государства в финансово-хозяйственной деятельности эмитента и наличие признаков противоправных действий органов корпоративного управления эмитента. В-третьих, специфические факторы на уровне облигации, включая тип дефолта, также оказывают значимое влияние на ставку восстановления.

\section{Список литературы}

1. Антонова Е.Н. Методы расчета ставки восстановления по корпоративным облигациям 
// Вестник ГУУ. № 18. 2012. С. 114-117.

2. Антонова Е.Н. Обзор моделей оценки ставки восстановления по корпоративным облигациям // Корпоративные финансы. № 1(17) . 2011. C.103-122. URL: http://ecsocman.hse.ru/mags/cfjournal.

3. Перечень системообразующих организаций. Пресс-служба Министерства экономического развития РФ. URL: http://www.economy.gov.ru/minec/press/doc1242311886548.

4. Уголовный кодекс РФ. М.: Эксмо, 2012.

5. Федеральный закон «О несостоятельности (банкротстве)» от 26.10.2002 № 127-Ф3. URL: http://www.consultant.ru/popular/bankrupt/58_1.html.

6. Acharya, V., Bharath, S., Srinivasan, A. (2003), Understanding the Recovery Rates of Defaulted Securities. URL: http://papers.ssrn.com/sol3/papers.cfm?abstract_id=442901.

7. Altman, E., Brady, B., Resti, A., Sironi, A. (2001), Analyzing and Explaining Default Recovery Rates, ISDA Research Report . URL: http://www.isda.org/c_and_a/pdf/Analyzing_Recovery_rates_010702.pdf.

8. Covitz, D., Han, S. (2004), An Empirical Analysis of Bond Recovery Rates: Exploring a Structural View of Default, Federal Reserve Board Division of Research and Statistics . URL: http://www.federalreserve.gov/pubs/feds/2005/200510/200510pap.pdf.

9. Eberhart, A., Weiss, L. (1998), The Importance of Deviations from the Absolute Priority Rule in Chapter 11 Bankruptcy Proceedings, Financial Management, 27 (4) (1998) 106-110.

10. Franks, J., Torous, W. (2000), A Comparison of Financial Restructuring in Distressed Exchanges and Chapter 11 Reorganisations, Journal of Financial Economics, 35(2000) 349370.

11. Frye, J. (2000), Collateral damage detected: A Source of Systematic Credit Risk, Working paper of Federal Reserve Bank of Chicago . URL: http://www.chicagofed.org/digital_assets/publications/risk_management_papers/sr_2000_15 .pdf.

12. Gupton, G.M., Stein, R.M. (2002), LossCalcTM: Model for Predicting Loss Given Default. Moody's KMV, New York.

13. Izvorski, I. (1997), Recovery Ratios and Survival Times for Corporate Bonds, Working Paper of International Monetary Eund. http://www.imf.org/external/pubs/ft/wp/wp9784.pdf.

14. Jacobs, M., Karagozoglu, A. (2010), Modeling Ultimate Loss-Given-Default on Bonds and Loans. URL: http://www.defaultrisk.com/pp_recov101.htm.

15. Schuermann, T. (2004), What Do We Know About Loss Given Default? The Wharton Financial Institutions Center . URL: http://fic.wharton.upenn.edu/fic/papers/04/0401.pdf.

16. Varma, P., Cantor, R. (2004), Determinants of Recovery Rates on Defaulted Bonds and Loans for North American Corporate Issuers: 1983-2003. Moody's Research. 